\title{
Airborne high spectral resolution lidar for measuring aerosol extinction and backscatter coefficients
}

\author{
Michael Esselborn, ${ }^{1, *}$ Martin Wirth, ${ }^{1}$ Andreas Fix, ${ }^{1}$ Matthias Tesche, ${ }^{2}$ and Gerhard Ehret ${ }^{1}$ \\ ${ }^{1}$ Institut für Physik der Atmosphäre, Deutsches Zentrum für Luft- und Raumfahrt (DLR), Oberpfaffenhofen, \\ 82234 Wessling, Germany \\ ${ }^{2}$ Leibniz-Institut für Troposphärenforschung (IFT), 04318 Leipzig, Germany \\ ${ }^{*}$ Corresponding author: Michael.Esselborn@dlr.de
}

Received 15 August 2007; revised 3 December 2007; accepted 3 December 2007; posted 4 December 2007 (Doc. ID 86422); published 14 January 2008

\begin{abstract}
An airborne high spectral resolution lidar (HSRL) based on an iodine absorption filter and a high-power frequency-doubled Nd:YAG laser has been developed to measure backscatter and extinction coefficients of aerosols and clouds. The instrument was operated aboard the Falcon 20 research aircraft of the German Aerospace Center (DLR) during the Saharan Mineral Dust Experiment in May-June 2006 to measure optical properties of Saharan dust. A detailed description of the lidar system, the analysis of its data products, and measurements of backscatter and extinction coefficients of Saharan dust are presented. The system errors are discussed and airborne HSRL results are compared to ground-based Raman lidar and sunphotometer measurements. (C) 2008 Optical Society of America
\end{abstract}

OCIS codes: $\quad 010.0280,010.1280,280.1100,280.3640,290.2200,290.5850$.

\section{Introduction}

Aerosols play a key role in the Earth's radiative budget because they directly influence the fluxes of solar and terrestrial radiation within the atmosphere by absorption and scattering of light [1]. The quantification of this effect accounts for accurate and highly resolved measurements of aerosol extinction and vertical distribution. Using a conventional backscatter lidar, aerosol extinction cannot be measured directly. Only with assumption of the aerosol extinction-tobackscatter ratio, the so-called lidar ratio, aerosol extinction coefficients can be retrieved by means of inversion algorithms [2]. However, the aerosol lidar ratio is a highly variable quantity, so that large errors in the retrieval must be expected if the lidar ratio is not known exactly. The only alternate lidar method to measure aerosol extinction profiles directly is Raman lidar [3]. The long averaging times associated with the Raman method, however, have prevented this technique from being used in airborne operation so far. Recently, ground-based demonstration measurements of the lidar ratio and other quantities with a

0003-6935/08/030346-13\$15.00/0

(C) 2008 Optical Society of America
Raman lidar specially developed for airborne operation have been reported [4]. A high spectral resolution lidar (HSRL) takes advantage of the different spectral broadening of light, backscattered by molecules and aerosols. By means of a narrow bandwidth optical filter the aerosol contribution is separated from the molecular backscatter. Thus, aerosol backscatter and extinction coefficients can be measured directly and no assumption about the lidar ratio is required. Up to now, only a few HSRL instruments have been proposed and successfully implemented to measure atmospheric parameters or particle properties. These utilize either narrow bandwidth interferometers [5] to reject aerosol scattering or atomic [6-8] and molecular [8-10] vapor filters. The advantages of iodine vapor filters are the strong rejection of aerosol backscatter at low cell temperatures and the marginal sensitivity to optical alignment and angular divergence of the backscattered light. Furthermore, they can be designed in compact dimensions and do not have to be pressure stabilized. Thus, iodine vapor filters are ideal candidates for airborne HSRL operation. Airborne HSRL measurements could be demonstrated by our group during the Lindenberg Aerosol Characterization Experiment (LACE) field campaign in 1998 using a $10 \mathrm{~Hz}$ single-mode Nd:YAG 
laser system aboard the German Aerospace Center (DLR) Falcon research aircraft [11]. This system was limited by the relatively low horizontal sampling capability, low aerosol attenuation within the singlepass iodine vapor cell and unstable laser frequency control. Recently, another HSRL based on a $200 \mathrm{~Hz}$ low-power Nd:YAG laser has been deployed during two field experiments aboard the NASA B200 King Air [12].

Here, we present a new airborne HSRL, which was applied during the Saharan Mineral Dust Experiment (SAMUM) field campaign in May-June 2006 to measure cross sections of extinction and backscatter coefficients of pure Saharan dust close to its source regions for the first time to the best of our knowledge. This system is operated at $100 \mathrm{~Hz}$ using a high-power $\mathrm{Nd}$ :YAG laser, which is frequency controlled by means of a new robust laser frequency stabilization. For stronger aerosol suppression a new iodine vapor filter in dual-pass configuration has been designed. The development of the HSRL system was partially driven by two forthcoming satellite missions of the European Space Agency (ESA). The Atmospheric Dynamics Mission (ADM [13]) will use a Doppler lidar, which is expected to also have potential for extinction profiling [14]. The EarthCARE mission [15] will employ a HSRL instrument at $355 \mathrm{~nm}$. The airborne HSRL measurements can be of great help to evaluate the potential and performance of the spaceborne instruments in advance. For validation purposes, airborne measurements can be coordinated and allow nearly real-time spatial overlap along the satellite footprint.

The purpose of this paper is a detailed description of our new airborne HSRL system, the retrieval method of its data products, an error analysis, and a presentation of measurement examples together with a comparison to ground-based Raman lidar and sunphotometer data. A detailed scientific analysis of the campaign's results will be the subject of a forthcoming paper.

\section{HSRL Theory and Data Retrieval}

The elastic scattering of light by particles small compared to the wavelength is usually described by Rayleigh scattering theory [16]. Besides the elastic part, atmospheric Rayleigh scattering [17] includes the frequency shifted rotational Raman bands associated with $\Delta J= \pm 2$ transitions, where $J$ is the rotational quantum number of the scattering molecule. The dominant central part of the backscatter spectrum, which arises from elastic scattering together with the unshifted $\Delta J=0$ rotational Raman branch make up the Cabannes line [18], which shows pressure and temperature-dependent Brillouin sidebands [19]. At atmospheric temperatures close to $300 \mathrm{~K}$ the Doppler broadening of the Cabannes line amounts to $2.6 \mathrm{GHz}$ for green light with a wavelength of $532 \mathrm{~nm}$. In contrast, aerosol backscatter is hardly broadened due to the relatively slow motion of aerosol particles, so that it can be characterized by the laser frequency distribution.
Using HSRL, the received atmospheric backscatter is split into two channels. The narrow bandwidth optical filter in the molecular channel suppresses the aerosol backscatter, whereas the combined channel detects the intensity of both aerosol and molecular backscatter. Therefore the emitted laser frequency must be tuned to match the filter absorption line. The iodine absorption filter eliminates the aerosol backscatter and transmits the wings of the Doppler broadened molecular backscatter spectrum. To determine the amount of molecular backscatter absorbed by the iodine filter, the HSRL system needs to be calibrated. This is done by measuring the filter transmission spectrum and calculating the atmospheric temperature and pressure-dependent filter transmission with an appropriate molecular backscatter model. For measuring the iodine filter transmission spectrum, a highly attenuated reflection of the pulsed green laser emission is directed through the receiver assembly and the laser frequency is scanned. The filter transmission is determined by the product of the iodine filter transmission and the calculated molecular backscatter spectrum. In our experiments the transmitted fraction of the molecular backscatter exceeds $30 \%$ for atmospheric temperatures higher than $200 \mathrm{~K}$ using iodine absorption line 1109 (line notation follows Ref. [20]). The partial transmission $\kappa_{m}(r)$ of the temperature- and pressure-dependent Cabannes spectrum $R(v, T, p)$ through the iodine vapor filter with transmission function $\tau(v)$ may be written as

$$
\kappa_{m}(T, p)=\frac{\int \tau(v) \int R\left(v^{\prime}, T, p\right) l\left(v-v^{\prime}\right) \mathrm{d} v^{\prime} \mathrm{d} v}{\int R\left(v^{\prime}, T, p\right) l\left(v-v^{\prime}\right) \mathrm{d} v^{\prime}},
$$

with $l(v)$ being the laser spectrum. Figure 1 shows the measured transmission of the iodine filter cell operated at a vapor pressure of $53 \mathrm{~Pa}$ as a function of frequency offset from the absorption maximum. The central absorption line is iodine line 1109. The mo-

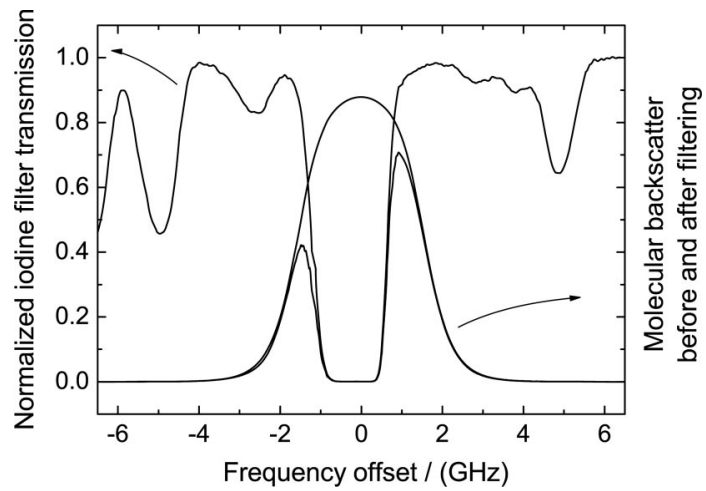

Fig. 1. Measured iodine transmission spectrum at $563.244 \mathrm{THz}$ together with molecular backscatter spectrum calculated with the S6-Tenti model for an atmospheric temperature of $300 \mathrm{~K}$ and pressure of $1000 \mathrm{hPa}$. 


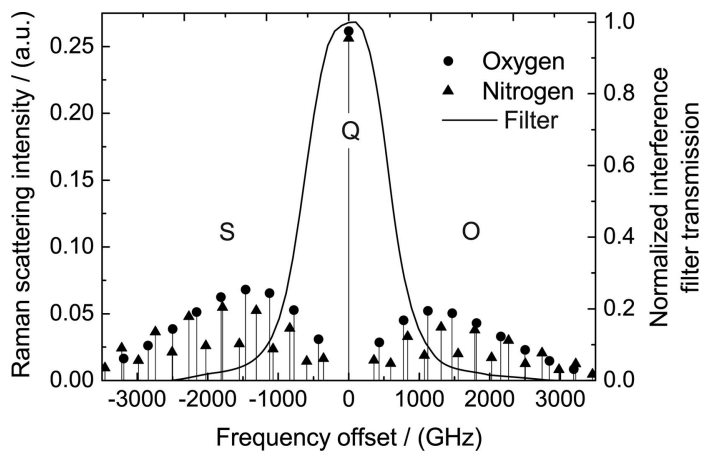

Fig. 2. Measured interference filter transmission and calculated rotational Raman spectrum at 563.244 $\mathrm{THz}$.

lecular backscatter spectrum was calculated with the S6 code provided by Tenti et al. [21] using a molecular mass of $28.8 \mathrm{~kg} / \mathrm{kmol}$ for air molecules. Due to the lack of experimentally verified data for air molecules, the molecular parameters for the ratio of shear viscosity to bulk viscosity and the ratio of shear viscosity to thermal conductivity of nitrogen [22] have been used. The result is given for an atmospheric temperature of $300 \mathrm{~K}$ and pressure of $1000 \mathrm{hPa}$. The transmitted fraction of molecular backscatter is the ratio of the integrals of the molecular spectrum before and after filtering. In the case of $T=300 \mathrm{~K}, p=$ $1000 \mathrm{hPa}$ the fraction amounts to $\kappa_{m}=0.430$.

Depending on the bandwidth of the background filter, spectral components arising from pure rotational Raman scattering have to be considered. Figure 2 shows the measured transmission function of the interference filter and the rotational Raman spectrum as a function of the frequency offset from the incident laser wavelength. The redshifted Stokes and the blueshifted anti-Stokes branch are denoted by $S$ and $O$, respectively. The full width at half-maximum (FWHM) of the interference filter is $1095 \mathrm{GHz}$. As can be seen, the first Stokes and anti-Stokes Raman line of oxygen and the first two lines of nitrogen are included within the FWHM of the filter. The central $Q$ branch of the rotational Raman spectrum adds to the Cabannes line $R(v, T, p)$ and has the same spectral broadening. Thus, it does not affect the calculation of $\kappa_{m}$. The shifted $O$ and $S$ branches contribute only $2.5 \%$ of the whole Rayleigh cross section. Their partial transmission through the background interference filter can be calculated. In our case, $5.7 \%$ of the shifted rotational Raman scattering intensity is transmitted through the filter. Raman scattering contributes less than $0.5 \%$ to the molecular channel intensity assuming that at least $1 / 3$ of the total Cabannes scattering is detected and the Raman bands are not attenuated by the iodine absorption spectrum. Therefore the small impact of Raman scattering on the backscatter calculation is neglected.

The other quantity measured through calibration is the transmission of aerosol backscatter in the molecular channel. This quantity decreases with increasing vapor pressure and optical path length within the filter cell. Assuming no spectral broaden- ing, the aerosol backscatter spectrum can be described by the laser frequency distribution. The laser's spectral width of $\approx 75 \mathrm{MHz}$ is small compared to the bandwidth of the iodine filter, which is $\approx 2 \mathrm{GHz}$ at typical filter conditions. Thus, the transmitted fraction of aerosol backscatter $\kappa_{a}$ through the filter can be regarded as the filter transmission at line center:

$$
\kappa_{a}=\tau\left(v_{0}\right) .
$$

The absorption within the iodine filter cell at line center is usually very strong and the experimental determination of $\kappa_{\alpha}$ is restricted by detector noise or stray light. With a model provided by Forkey et al. $[23,24]$, iodine absorption spectra at $532 \mathrm{~nm}$ can be calculated for different cell lengths and temperatures. For our HSRL experiments the calculated aerosol transmission is typically of the order of $10^{-6}$ $<\kappa_{a}<10^{-5}$. As will be shown in Subsection 3.B, our receiver module is laid out for polarization sensitive detection. At first, the received atmospheric backscatter is split into its parallel (superscript $\|$ ) and cross-polarized (superscript $\perp$ ) components. The parallel-polarized channel is split again into the combined channel (subscript $C$ ) and the molecular channel (subscript $M$ ). The received power from distance $\tau$ in the three measurement channels can be written as

$$
\begin{aligned}
& P_{C}^{\|}(r)=\eta_{C} E_{0} E^{\|} \frac{c}{2} \frac{A}{r^{2}} \tau^{2}(r)\left[\beta_{m} \|(r)+\beta_{a}^{\|}(r)\right], \\
& P_{M}^{\|}(r)=\eta_{M}{ }^{\|} E_{0}{ }_{0} \frac{c}{2} \frac{A}{r^{2}} \tau^{2}(r)\left[\kappa_{m}(r) \beta_{m}{ }_{m}^{\|}(r)+\kappa_{a} \beta_{a} \|(r)\right], \\
& P^{\perp}(r)=\eta^{\perp} E_{0} \frac{c}{2} \frac{A}{r^{2}} \tau^{2}(r)\left[\beta_{m}{ }^{\perp}(r)+\beta_{a}{ }^{\perp}(r)\right],
\end{aligned}
$$

where $\eta$ denotes the channel efficiency, $c$ is the speed of light, $A$ is the telescope aperture; $E_{0}{ }^{\|}$is the pulse energy, $\tau^{2}(r)$ is the two-way atmospheric transmission over range $r$ from the lidar transmitter to the scattering event, and $\beta_{m, a}^{\|, \perp}(r)$ denotes the parallel and perpendicular backscatter coefficients of molecules and aerosols. Note that $\kappa_{m}(r)$ is a function of height due to its dependence on atmospheric temperature and pressure. The atmospheric transmission is composed of a molecular and an aerosol contribution,

$$
\begin{aligned}
\tau^{2}(r) & =\tau_{m}{ }^{2}(r) \tau_{a}^{2}(r) \\
& =\exp \left[-2 \int_{0}^{r}\left(\alpha_{m}\left(r^{\prime}\right)+\alpha_{a}\left(r^{\prime}\right)\right) \mathrm{d} r^{\prime}\right],
\end{aligned}
$$

where $\alpha_{m, a}(r)$ denotes the molecular and aerosol extinction coefficient. Molecular and aerosol absorption effects can be neglected at the used lidar wavelength of $532 \mathrm{~nm}$. Following Rayleigh scattering theory [17], $\alpha_{m}(r)$ is strictly proportional to $\beta_{m}(r)$, 


$$
\alpha_{m}(r)=\frac{8 \pi}{3} \frac{(45+10 \epsilon)}{(45+7 \epsilon)} \beta_{m}(r)
$$

where $\epsilon(532 \mathrm{~nm})=0.222$ accounts for molecular anisotropy [25]. $\beta_{m}(r)$ is given by the product of the differential backscattering cross section $\partial \sigma(\pi) / \partial \Omega$ and the number density $N(r)$ of the scatterers [26]

$$
\beta_{m}(r)=\frac{\partial \sigma(\pi)}{\partial \Omega} N(r)
$$

where $N(r)$ can be calculated from measured temperature and pressure data or from standard atmosphere profiles. The Rayleigh scattering properties of the atmospheric gas composition are wellknown and tabulated in the literature [25,27]. The total Rayleigh scattering cross section at $532 \mathrm{~nm}$ amounts to $\sigma=5.16 \times 10^{-31} \mathrm{~m}^{2}$ as interpolated from data given in Ref. [27]. The differential backscattering cross section of the Cabannes line only amounts to $\partial \sigma(\pi) / \partial \Omega=5.93 \times 10^{-32} \mathrm{~m}^{2} \mathrm{sr}^{-1}$ at $532 \mathrm{~nm}$. However, the effectively detected cross section depends on the spectral and polarization properties of the receiver because of the depolarization of the rotational Raman lines and their spectral separation. As already stated the rotational Raman lines partially transmit through the interference filter. For the background interference filter and the polarization beam splitters in our receiver the value of the differential backscattering cross section reduces to 5.91 $\times 10^{-32} \mathrm{~m}^{2} \mathrm{sr}^{-1}$.

To determine the amount of total (parallel and cross-polarized) backscatter, which is required for depolarization data processing, the measured powers in the parallel-polarized combined channel and the cross-polarized channel has to be calculated:

$$
P^{T}(r)=P_{C}^{\|}+\frac{\eta_{C}^{\|}}{\eta^{\perp}} P^{\perp}(r)
$$

To determine the relative sensitivity factor $\eta_{C}^{\|} / \eta^{\perp}$ a calibration during the measurement flight is required. Therefore the receiver module is rotated by an angle of $45^{\circ}$, such that the plane of polarization of both the parallel and the cross-polarized channel is rotated by $45^{\circ}$ relative to the transmitter's plane of polarization. $\eta_{C}^{\|} / \eta^{\perp}$ is then calculated from the ratio of the signal intensities in the parallel and crosspolarized channel. To obtain the aerosol extinction and backscatter coefficients from the measured signals given in Eqs. (3)-(5) and (9), the signals are multiplied by $r^{2}$ for range correction and divided by $\left[\tau_{m}{ }^{2}(r) \times \beta_{m}(r)\right]$ to account for molecular extinction and backscatter, respectively. Moreover, the signals are normalized to the power received from a region at distance $r_{0}$ where the aerosol concentration can be neglected, i.e., $\beta_{a}\left(r_{0}\right) \approx 0$, whereby all constants cancel out. Hence, an attenuated backscatter ratio $R$, which is the backscatter ratio $\left[1+\beta_{a}(r) / \beta_{m}(r)\right]$ multiplied by aerosol transmission is defined as
$R_{C} \|(r)=\frac{P_{C}^{\|}(r)}{C_{C} \|} \frac{r^{2}}{\tau_{m}{ }^{2}(r) \beta_{m}{ }^{\|}(r)}=\tau_{a}^{2}(r)\left[1+\frac{\beta_{a}^{\|}(r)}{\beta_{m} \|(r)}\right]$,

$R_{M} \|(r)=\frac{P_{M} \|(r)}{C_{M} \|} \frac{r^{2}}{\tau_{m}^{2}(r) \beta_{m} \|(r)}=\tau_{a}^{2}(r)\left[\kappa_{m}(r)+\kappa_{a} \frac{\beta_{a}^{\|}(r)}{\beta_{m} \|(r)}\right]$

$R^{T}(r)=\frac{P^{T}(r)}{C^{T}} \frac{r^{2}}{\tau_{m}{ }^{2}(r) \beta_{m}{ }^{T}(r)}=\tau_{a}{ }^{2}(r)\left[1+\frac{\beta_{a}{ }^{T}(r)}{{\beta_{m}}^{T}(r)}\right]$,

where $\beta_{m, a}{ }^{T}(r)$ denotes the total (parallel and crosspolarized) molecular and aerosol backscatter coefficients. The constant $C_{C, M} \|, T$ for each channel is chosen to set $R_{C}^{\|}\left(r_{0}\right)$ and $R^{T}\left(r_{0}\right)$ close to 1 and $R_{M} \|\left(r_{0}\right)$ to the value of $\kappa_{m}\left(r_{0}\right)$. The constant is composed of $C_{C, M} \|, T$ $=\eta_{C, M},\left\|, T E_{0}\right\| A(c / 2)$ and calculated for each profile. Equations (10) and (11) are used to express the twoway aerosol transmission by the two measured quantities and the calibration constants:

$$
\tau_{a}^{2}(r)=\frac{R_{M}^{\|}(r)-\kappa_{a} R_{C}^{\|}(r)}{\kappa_{m}(r)-\kappa_{a}} .
$$

The aerosol extinction coefficient $\alpha_{a}(r)$ follows from aerosol optical thickness (AOT) $t_{a}(r)$ by differentiation:

$$
\begin{aligned}
t_{a}(r) & =-\frac{1}{2} \ln \left[\tau_{a}^{2}(r)\right], \\
\alpha_{a}(r) & =\frac{\partial}{\partial r} t_{a}(r) .
\end{aligned}
$$

To calculate the numerical derivative of the AOT profile, a Savitzky-Golay filter [28] of first order is used. This is equivalent to a linear regression on a specified number of data points within a moving window. The slope of the fitted straight line in each point is taken as the value of the derivative. This differentiation method tends to preserve slopes and edges in the AOT profile, which would be flattened by adjacent averaging techniques.

To determine the total aerosol backscatter coefficient $\beta_{a}^{T}(r)=\beta_{a}^{\|}(r)+\beta_{a}{ }^{\perp}(r)$ from the three measured signals given in Eqs. (3)-(5), the aerosol depolarization ratio $\delta_{a}(r)$ has to be analyzed first. Therefore the equation given in [29] is used:

$$
\delta_{a}(r)=\frac{\beta_{a}{ }^{\perp}(r)}{\beta_{a}{ }^{\|}(r)}=\frac{\left[1+\delta_{m}\right] \delta_{v}(r) R^{T}(r) / \tau_{a}{ }^{2}(r)-\left[1+\delta_{v}(r)\right] \delta_{m}}{\left[1+\delta_{m}\right] R^{T}(r) / \tau_{a}{ }^{2}(r)-\left[1+\delta_{v}(r)\right]},
$$

where $\delta_{m}$ denotes the volume depolarization ratio of molecular backscatter and $\delta_{v}(r)$ the volume depolarization ratio of total backscatter defined as 


$$
\delta_{v}(r)=\frac{\eta_{C}^{\|}}{\eta^{\perp}} \frac{P^{\perp}(r)}{P_{C}^{\|}(r)} .
$$

The value of $\delta_{m}$ is highly dependent on the amount of detected pure rotational Raman scattering and varies between $3.63 \times 10^{-3}$ and $1.43 \times 10^{-2}$ depending on the detection of the Cabannes line alone or the full inclusion of the pure rotational Raman bands, respectively [30]. As has been discussed before, our interference filters partially transmit the rotational Raman spectrum and the value of $\delta_{m}$ has been calculated to $6.8 \times 10^{-3}$. Finally, the total aerosol backscatter coefficient can be expressed by

$$
\beta_{a}{ }^{T}(r)=\left[\frac{R_{C}{ }^{\|}(r)}{\tau_{a}^{2}(r)}-1\right] \beta_{m}{ }^{\|}(r)\left(1+\delta_{a}(r)\right) .
$$

The aerosol lidar ratio $S_{a}(r)$ is defined as the ratio of the aerosol extinction coefficient to the backscatter coefficient:

$$
S_{a}(r)=\frac{\alpha_{a}(r)}{\beta_{a}^{T}(r)} .
$$

Unlike the constant molecular lidar ratio, the aerosol lidar ratio generally varies with height because it depends on the aerosol size distribution, its shape, and chemical composition [31,32].

\section{System Description}

\section{A. Transmitter}

The HSRL described in this paper has been developed as an extension of the existing airborne DLR water vapor differential absorption lidar (DIAL) system [33]. The laser transmitter used for the HSRL measurements is a high-power, $Q$-switched Nd:YAG laser in a master-oscillator power amplifier configuration. It consists of a low-power master oscillator and three power amplifiers yielding a pulse energy of $220 \mathrm{~mJ}$ at $1064 \mathrm{~nm}$ and a repetition rate of $100 \mathrm{~Hz}$. A schematic of the HSRL transmitter is shown in Fig. 3.

A detailed description of the laser system can be found in Ehret et al. [34]. To obtain single longitudi-

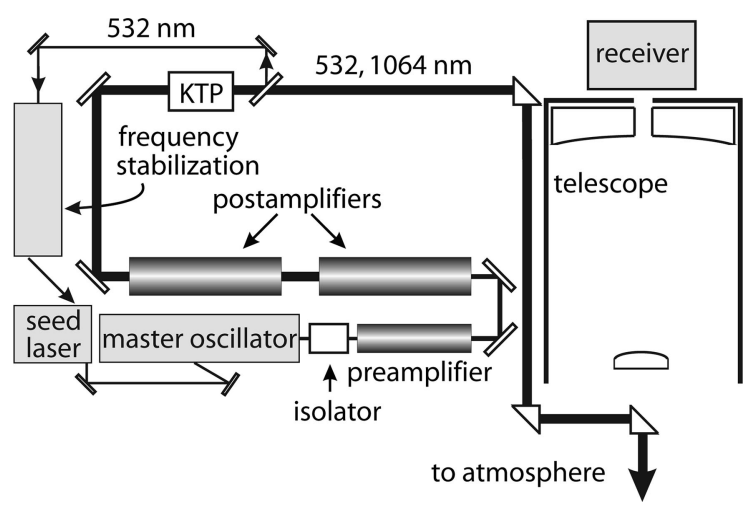

Fig. 3. Schematic of the transmitter system.
Table 1. System Parameters of the HSRL System

$\begin{array}{ll}\text { MOPA Laser system } & \\ \text { Pulse energy at } 1064 \mathrm{~nm} & 220 \mathrm{~mJ} \\ \text { Repetition rate } & 100 \mathrm{~Hz} \\ \text { Pulse width at } 1064 \mathrm{~nm} & 18 \mathrm{~ns} \\ \text { Linewidth at } 1064 \mathrm{~nm} & <75 \mathrm{MHz} \\ \text { Laser divergence at } 1064 \mathrm{~nm} & 0.5 \mathrm{mrad} \\ \text { SHG } & \\ \text { Pulse energy at } 532 \mathrm{~nm} & 100 \mathrm{~mJ} \\ \text { Frequency fluctuations } & <5 \mathrm{MHz} \\ \text { Spectral purity } & 99.96 \% \\ \text { Receiver } & \\ \text { Telescope diameter } & 350 \mathrm{~mm} \\ \text { Background filter bandwidth } & 1 \mathrm{THz} \\ \text { Iodine absorption bandwidth } & 2 \mathrm{GHz} \\ \text { Optical iodine filter length } & 380 \mathrm{~mm} \\ \text { Detector divergence } & 1 \mathrm{mrad} \\ \text { PMT quantization } & 14 \mathrm{bits} \\ \text { PMT sampling rate } & 10 \mathrm{MHz}\end{array}$

nal mode operation the master oscillator is injection seeded by a monolithic Nd:YAG ring laser and stabilized by minimizing the $Q$-switch build-up time [35]. The seed laser frequency is tuned by changing the $\mathrm{Nd}$ :YAG crystal temperature. The fundamental radiation of the pulsed laser is frequency-doubled using a temperature stabilized KTP crystal yielding a pulse energy of $110 \mathrm{~mJ}$. An attenuated reflection of the green radiation is directed to a frequency stabilizer that continuously controls the temperature of the seed laser. The stabilization method is based on acousto-optic modulation and locks the green laser radiation to a Doppler-broadened iodine absorption line. The advantage of this frequency stabilization technique is the monitoring and stabilization of the amplified laser output instead of the seed laser frequency. With this new method long-term frequency fluctuations have been reduced to $\Delta v=4.8 \mathrm{MHz}$ or in relative terms $\Delta v / v=8.5 \times 10^{-9}$ during airborne operation. Table 1 summarizes the system properties.

\section{B. Receiver}

The atmospheric backscatter is collected by means of a $350 \mathrm{~mm}$ Cassegrain telescope. A field stop within the focal plane of the telescope limits the acceptance angle to $1 \mathrm{mrad}$. Dichroic beam splitters are used to spectrally separate the backscatter signals at 1064 and $532 \mathrm{~nm}$. The part of the receiver that detects atmospheric backscatter at $532 \mathrm{~nm}$ is schematically shown in Fig. 4. The received light is split into its polarized components with a polarizing beam splitter cube. The cross-polarized component is directed to photomultiplier PMT3 whereas the parallelpolarized component is transmitted. In both paths a second polarizing beam splitter is placed to reduce polarization cross talk. The transmitted parallel component of the backscatter signal is split again, such that half of its energy is directed into the molecular channel. 


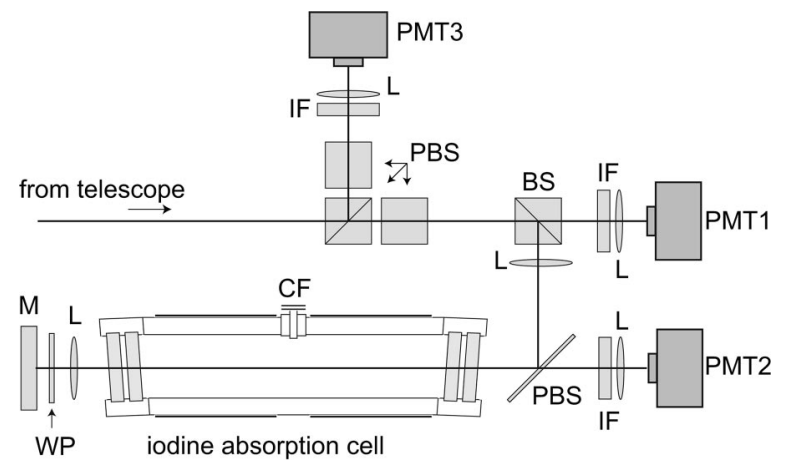

Fig. 4. Schematic of the receiver module used for detection at $532 \mathrm{~nm}$. BS, beam splitter; CF, cool finger; IF, interference filter; L, lens; M, mirror; PBS, polarization beam splitter; PMT, photomultiplier; WP, quarter-wave plate.

The other part is guided to PMT1 to measure the intensity of the combined backscatter. Within the molecular channel light travels through the iodine vapor cell and is reflected at a $0^{\circ}$ mirror. The plane of polarization is rotated by $90^{\circ}$ using a quarter-wave plate in dual pass, so that a polarizing beam splitter plate allows the reflected light to be transmitted onto PMT2. By means of the two-way pass, the optical path inside the iodine vapor cell is doubled, so that the geometric dimensions are kept small and stronger absorption is achieved without increasing the iodine vapor pressure. Thus, self-pressure broadening of the iodine absorption line is reduced and less of the wings of the molecular backscatter spectrum is blocked. The geometric length of the filter cell is $190 \mathrm{~mm}$. It is temperature stabilized and a cool finger kept at lower temperatures than the ambient cell is used to control the iodine vapor pressure. Because the amount of absorbing iodine in the gas phase sensitively depends on the cool finger's temperature, it has to be stabilized with high accuracy. The HSRL experiments were conducted with cool finger temperatures ranging from $28{ }^{\circ} \mathrm{C}$ to $45^{\circ} \mathrm{C}$ resulting in vapor pressures between 53 and $159 \mathrm{~Pa}$. The ambient cell was kept at temperatures $5^{\circ}$ higher than the cool finger to avoid sublimation of iodine vapor. The cell windows are wedged and antireflection coated to avoid interference effects between the window surfaces. At each end of the cell there is an additional window for thermal isolation.

The receiver module also provides avalanche photodiodes (APDs) for the detection of $1064 \mathrm{~nm}$ parallel and cross-polarized backscatter (not shown in Fig. 4). A further APD is installed for measurements at $935 \mathrm{~nm}$ in case water vapor measurements are conducted simultaneously using the DIAL technique [33]. Here we focus only on HSRL operation. The quantities measured with this instrument are profiles of extinction and backscatter coefficients at $532 \mathrm{~nm}$, linear depolarization at 532 and $1064 \mathrm{~nm}$, and attenuated backscatter at $1064 \mathrm{~nm}$ with high horizontal and vertical resolution. Thus, the atmospheric aerosol can be characterized and classified by its lidar ratio, its depolarization ratio, and its green- to-infrared backscatter ratio. All these quantities do not depend on aerosol concentration. Another unique feature of an airborne HSRL is its ability to measure the horizontal variation of aerosol optical thickness along the flight path.

\section{Case Study of Results from the Saharan Mineral Dust Experiment}

The SAMUM is a joint research project of several German institutes aiming at the characterization of Saharan dust referring to its optical, microphysical, chemical, and radiative properties. The first field phase of the SAMUM took place in May-June 2006 in southern Morocco including ground stations in Ouarzazate $\left(30.9^{\circ} \mathrm{N}, 6.9^{\circ} \mathrm{W}\right)$ and Zagora $\left(30.3^{\circ} \mathrm{N}, 5.8^{\circ} \mathrm{W}\right)$ from where ground-based measurements with active and passive remote sensing as well as in situ instruments were conducted. Two research aircraft were engaged during the first SAMUM field phase. Equipped with the nadir-viewing HSRL and an extensive set of aerosol in situ probing instruments, the DLR Falcon research aircraft performed airborne measurements of various dust properties. During the first SAMUM field phase, the DLR Falcon aircraft was stationed in Casablanca from where science flights started either southbound to sound the atmosphere over the ground stations or northbound for observation of long-range transport of desert dust. In total eight measurement flights were performed during the first SAMUM field phase. For validation purposes, airborne HSRL measurements were compared to ground-based Raman lidar and sunphotometer measurements conducted by the Leibniz Institute for Tropospheric Research (IFT) at Ouarzazate. In the following, the performance of the HSRL will be shown on the basis of two case studies.

Figure 5 shows the route of the DLR Falcon research aircraft on 4 June with takeoff at 09:15 UTC in Casablanca. The flight altitude is color coded in the diagram. The main objectives of this flight mission were to measure the vertical and horizontal distribution of Saharan dust south of the High Atlas moun-

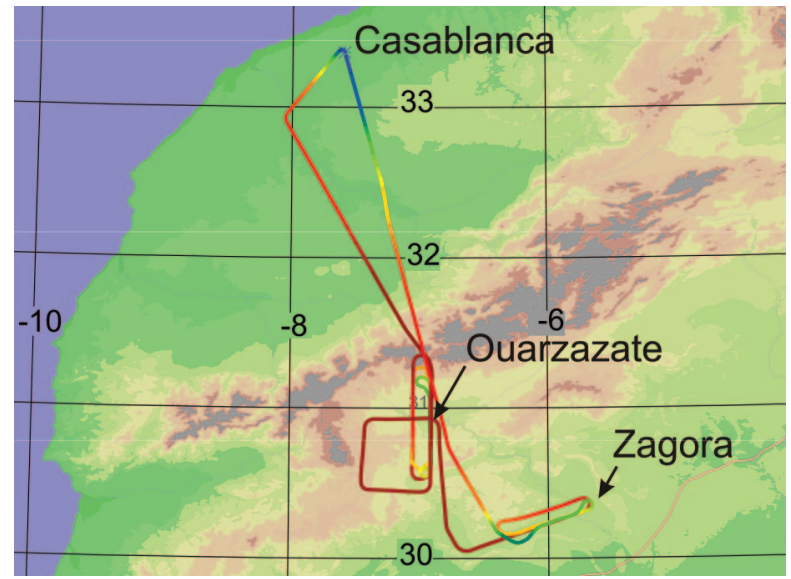

Fig. 5. Flight path of the DLR Falcon on 4 June between 09:15 and 12:35 UTC. The flight level is color coded. 
HSRL Backscatter Ratio at $532 \mathrm{~nm}$ (|| - Polarization)
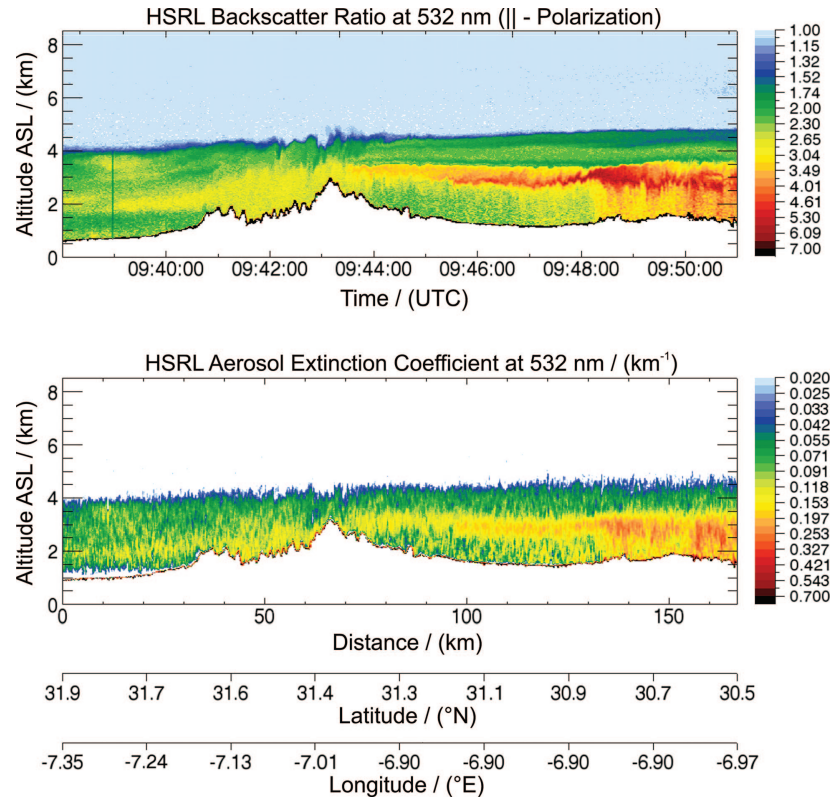

Fig. 6. North-south cross section of the HSRL backscatter ratio and the aerosol extinction coefficient during the measurement flight on 4 June 2006 at 09:45 UTC. The altitude is above sea level.

tain range at high altitude over Ouarzazate and Zagora and to conduct in situ measurements at several lower levels within the dust layer. Moreover, the flight was coordinated with satellite overpasses of the multiangle imaging spectroradiometer (MISR) and the medium resolution imaging spectrometer (MERIS) for validation purposes. Figure 6 shows the cross sections of the HSRL backscatter ratio and aerosol extinction coefficient measured during the first flight leg at high altitude over Ouarzazate. The mean flight altitude on this leg extending over 165 $\mathrm{km}$ from north to south was $9.3 \mathrm{~km}$ above sea level (ASL). The dust distribution south of the High Atlas mountain range shows a complex stratified structure. In the backscatter ratio cross section several separate layers can be distinguished. The uppermost layer exceeds a height of $4.5 \mathrm{~km}$ ASL. The southern part of the cross section shows a distinct dust plume with a maximum aerosol concentration at $3 \mathrm{~km}$ ASL. The backscatter ratio of the parallel-polarized combined channel ranges from 2 up to 6 within the different layers. The extinction coefficient cross section shows characteristics similar to the backscatter cross section. The aerosol extinction coefficient reaches values of up to $0.25 \mathrm{~km}^{-1}$ within the layers of high dust loading. The comparatively high noise level in this diagram is due to the numerical differentiation necessary to derive the extinction coefficient from the AOT.

Figure 7 shows an average of the lidar signals measured in the parallel-polarized combined and molecular channel as a function of distance from the transmitter. These signals were averaged over $13 \mathrm{~s}$ around $09: 48 \mathrm{UTC}$ at $30.85^{\circ} \mathrm{N},-6.90^{\circ} \mathrm{E}$. A total of 25 profiles were averaged from which each profile is the

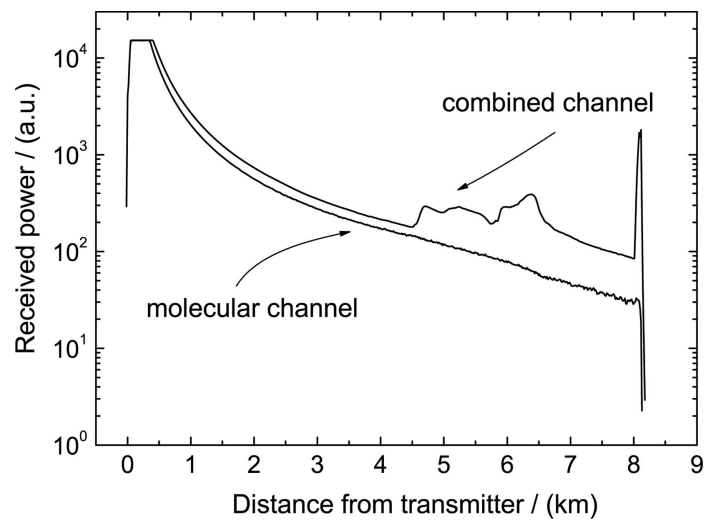

Fig. 7. Measured atmospheric backscatter in the parallelpolarized combined and molecular channel as a function of distance from transmitter averaged over $13 \mathrm{~s}$ on 4 June 2006.

mean profile of 52 laser shots. For background light correction the mean pretrigger value is subtracted from the measured raw data profiles. Both signals show the quadratic decay with distance. The signal in the combined channel features the structures of the aerosol layers and the ground echo, whereas the signal in the molecular channel decreases monotonically. These two signals are the basis of retrieving the aerosol backscatter and extinction coefficients. The transmitted fraction of aerosol backscatter through the iodine filter strongly depends on the injection seeding conditions of the master oscillator and generally can vary during airborne operation. Hence, a more appropriate way to determine $\kappa_{a}$ is to analyze the ground return detected in both channels. For this purpose the two channels are cross calibrated to adjust the same sensitivity and the ratio of the ground return detected in both channels is analyzed. In this case $\kappa_{a}$ is determined to be $<5 \times 10^{-4}$.

Figure 8(a) shows the profiles of the attenuated backscatter ratio determined from these signals. The parallel-polarized combined channel indicates the different aerosol layers with a top layer height of 4.7 $\mathrm{km}$ as well as the ground level at $1.3 \mathrm{~km}$ ASL. The backscatter ratio of the parallel-polarized molecular channel slightly increases along with temperature in the free troposphere and declines monotonically within the dust layer due to aerosol extinction. For calibration of the molecular channel, the iodine absorption spectrum of the filter was measured during the flight and the partial transmission of molecular backscatter through the iodine cell $\kappa_{m}(T, p)$ was calculated using the Tenti code [21]. The profiles of atmospheric temperature and pressure were taken from a radiosonde launched at Ouarzazate the same day at 10:39 UTC. For normalization of the combined channel signal, a background backscatter coefficient of $1 \times 10^{-5} \mathrm{sr}^{-1} \mathrm{~km}^{-1}$ was assumed in the free troposphere at $8.3 \mathrm{~km}$ ASL. This value corresponds to a backscatter ratio of 1.005 . At this height complete overlap of the transmitter's and the laser's field of view is assured and no stratification due to the presence of aerosols was observed in the backscatter sig- 

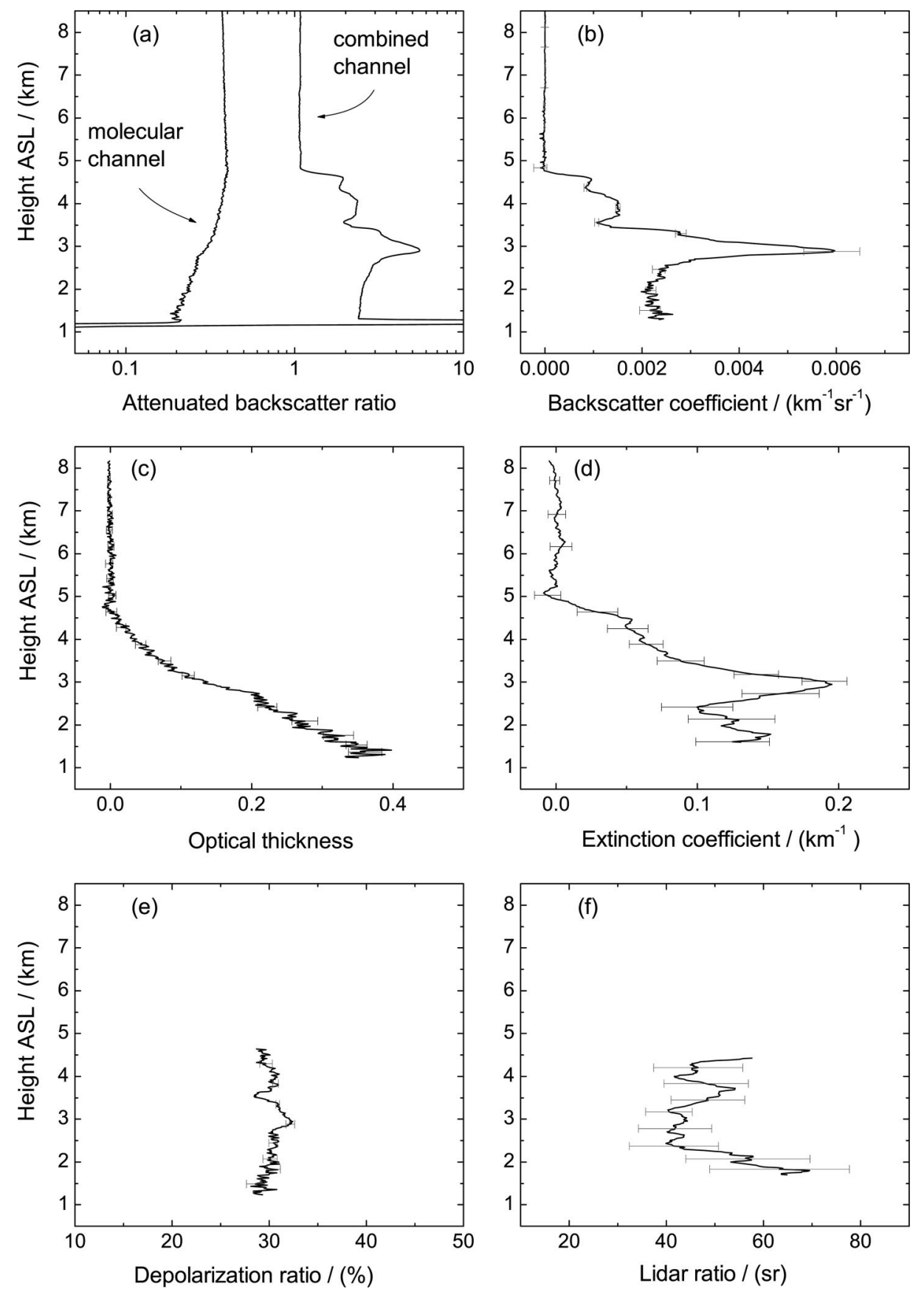

Fig. 8. (a) Backscatter ratio of the parallel-polarized molecular and combined channel, (b) total aerosol backscatter coefficient, (c) aerosol optical thickness, (d) aerosol extinction coefficient, (e) aerosol depolarization ratio, (f) lidar ratio. Profiles averaged over 13 s on 4 June 2006. Vertical resolution is $15 \mathrm{~m}$ except $540 \mathrm{~m}$ for (d) and (f). The error bars denote the $3 \sigma$ statistical deviation.

nals. The assumption of the background backscatter coefficient was based on the analysis of the in situ measurement of the aerosol size distribution. The in situ instrumentation included a set of condensation particle counters (CPC) partially connected to diffusion screens (size range $>5 \mathrm{~nm}$ ), a passive cavity aerosol spectrometer probe (PCASP $100 \times$, size range $0.1-3 \mu \mathrm{m})$ and a forward scattering spectrometer probe (FSSP 300 , size range $0.3-20 \mu \mathrm{m}$ ) to measure the aerosol size distribution with particle diameters ranging from $0.005-20 \mu \mathrm{m}$. The background back- scatter coefficient was calculated using the aerosol size distribution measured at flight altitude during 09:38 and 09:50 UTC by means of an inversion algorithm [36] to be $0.6 \times 10^{-5} \mathrm{sr}^{-1} \mathrm{~km}^{-1}$.

Figure 8(b) shows the total backscatter coefficient as calculated using Eq. (18). The vertical resolution is $15 \mathrm{~m}$. The error bars indicate the $3 \sigma$ statistical deviation from the average. The statistical deviation is based on the variance of the signals including the atmospheric variability among shot and electronic noise. The backscatter coefficient of the distinct 
dust plume at $3 \mathrm{~km}$ ASL amounts to $(5.9 \pm 0.5)$ $\times 10^{-3} \mathrm{sr}^{-1} \mathrm{~km}^{-1}$. The relatively large statistical error within this dust layer is attributed to atmospheric variations within the distance of approximately $3 \mathrm{~km}$ traveled with the aircraft during the averaging time. Figure 8(c) shows the increase of AOT from the free troposphere toward the ground with the error bars indicating the $3 \sigma$ deviation from the mean. Within the dust plume at $3 \mathrm{~km}$ ASL the AOT profile shows the steepest increase with height, indicating maximum aerosol extinction at this altitude. At ground level the AOT amounts to $0.37 \pm 0.02$, i.e., approximately $1 / 3$ of the impinging green radiation is scattered and absorbed by the dust loaded atmosphere. For calculation of the extinction coefficient the AOT profile is differentiated with respect to height using a Savitzky-Golay filter of first order. A total of 51 range bins is used for the filter resulting in a FWHM of the filter kernel of $540 \mathrm{~m}$. Figure 8(d) shows the corresponding extinction coefficient profile. The error bars indicate the $3 \sigma$ deviation from the mean with regard to the noise reducing property of the smoothing kernel.

Figure 8(e) shows the aerosol depolarization ratio of the dust from ground to $4.5 \mathrm{~km}$ ASL. As can be seen, the aerosol depolarization ratio shows only a little variation over the entire dust layer from ground to $4.7 \mathrm{~km}$ ASL. The values range from $28 \%$ to $32 \%$ and the error bars denote the $3 \sigma$ statistical deviation. For calculating the lidar ratio, the vertically highly resolved backscatter coefficient profile was smoothed in order to adjust its vertical resolution to that of the extinction coefficient profile. The vertical variation of the lidar ratio is shown in Fig. 8(f). The lidar ratio profile has a minimum value of 41 sr within the distinct dust layer at $3 \mathrm{~km}$ ASL. Toward the ground and the upper layers the lidar ratio increases to $55 \mathrm{sr}$ within the uppermost layer and around $60 \mathrm{sr}$ at the lowest layer. Both the aerosol depolarization and the lidar ratio do not depend on concentration and can thus be used for aerosol characterization.

\section{Error Analysis}

Systematic errors in the measurement of the backscatter coefficient may arise from uncertainties of the measured quantities $R_{C}{ }^{\|}(r), R_{M}{ }^{\|}(r), \delta_{a}(r)$ and the calculated quantities $\kappa_{m}(r), \kappa_{a}(r), \beta_{m}^{\|}(r)$. The uncertainty $\Delta R_{C}^{\|}(r)$, is mainly due to normalization, where the magnitude of background aerosol at a reference height within the free troposphere has to be estimated. For error calculation, the background aerosol coefficient was estimated to range from zero (pure molecular scattering) to the double value used for the analysis in Section 4. As stated before, the assumption of the background backscatter coefficient was based on the analysis of in situ measured aerosol size distributions. Comparisons with lidar measurements have shown that the deviation of calculated from measured data is $\sim 30 \%$ [37]. However, the background aerosol is close to the detection limit of the inversion method. Thus, the rather large error bounds were chosen to include the error of the calcu-

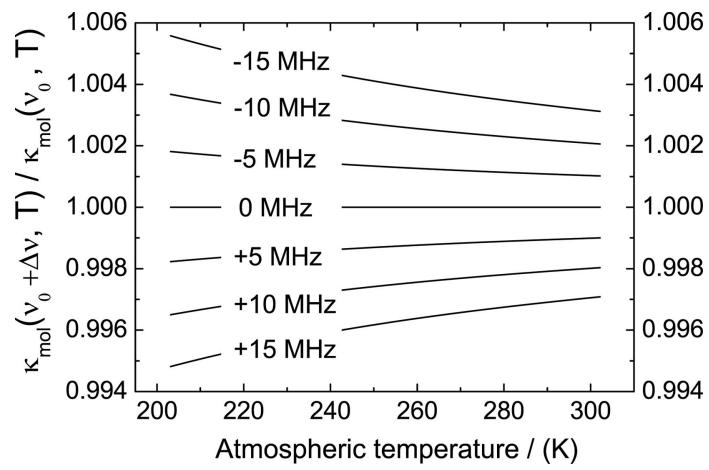

Fig. 9. Relative deviation of $\kappa_{m}(\nu, T)$ induced by laser frequency fluctuations of $\pm 5, \pm 10$, and $\pm 15 \mathrm{MHz}$, respectively.

lated backscatter coefficient. The uncertainty $\Delta \kappa_{m}(r)$ is mainly induced by laser frequency fluctuations and variations in the atmospheric temperature. Figure 9 shows the relative deviation of $\Delta \kappa_{m}(T)$ for laser frequency offsets from -15 to $+15 \mathrm{MHz}$. As can be seen, the relative deviations of $\kappa_{m}(T)$ decrease with temperature, i.e., the frequency fluctuations become less significant with the increasing Doppler broadening of the molecular backscatter spectrum. Though the long-term laser frequency fluctuations were kept below $+15 \mathrm{MHz}$, these bounds include short-term frequency variations inherent to the $Q$-switch buildup-time reduction technique. The variation of the atmospheric temperature profile was determined by the difference of the radiosonde measurement at 10:39 UTC and the aircraft temperature measurement during a dive at 09:50 UTC. The mean temperature difference was $0.8 \mathrm{~K}$ over the measurement range down to $1.9 \mathrm{~km}$ ASL. For error calculation a temperature uncertainty of $1 \mathrm{~K}$ was chosen.

The uncertainties $\Delta \kappa_{a}$ and $R_{M}^{\|}(r)$ are mainly caused by changes in the laser's spectral purity due to multimode laser shots. As already described, the spectral purity is derived from the average transmission of the ground return through the iodine filter during the measurement interval. The error $\Delta \kappa_{a}$ is determined from the statistical deviation of the filter transmission of each of the 25 profiles from the average value and amounts to $2 \times 10^{-4}$. The uncertainty of the aerosol depolarization ratio $\Delta \delta_{\alpha}(r)$ is mainly due to the accuracy of the $45^{\circ}$ calibration measurement. The mechanical precision and the reproducibility of the initial adjustment is estimated with a tolerance of $0.6^{\circ}$ resulting in a nearly constant error of the aerosol depolarization ratio profile of 4 percentage points. Table 2 summarizes the error sources and their estimated uncertainties.

To show the specific influence of the individual error sources, their contribution to the relative systematic error has been calculated separately. Figure 10(a) shows the profiles of the relative systematic errors of the backscatter coefficient shown in Fig. 8(b) caused by the individual error sources. For error calculation, the uncertainties listed in Table 2 were used. As can be seen the uncertainty in the depolar- 


\begin{tabular}{ll}
\hline \multicolumn{1}{c}{ Parameter } & \multicolumn{1}{c}{ Estimate } \\
\hline Background aerosol backscatter coefficient & $0<\beta_{a}\left(r_{0}\right)<2 \times 10^{-5} \mathrm{~km}^{-1} \mathrm{sr}^{-1}$ \\
Laser frequency drift & $\pm 15 \mathrm{MHz}$ \\
Laser spectral purity & $99.96 \% \pm 0.03 \%$ \\
Angular tolerance of depolarization calibration & $0.6^{\circ}$ \\
Atmospheric temperature & $\pm 1 \mathrm{~K}$ \\
\hline
\end{tabular}

ization measurement induces the largest individual error of $\approx 3 \%$ over the dust layer. Laser frequency fluctuations, uncertainties associated with the normalization and the atmospheric temperature cause relative errors between $1 \%$ and $2.5 \%$. Under these conditions the variations of the laser's spectral purity have the least impact on the backscatter measurement. To calculate the total systematic error the individual errors have been added in quadrature, i.e., as the square root of the sum of the squares. This has been done assuming statistically independent influence of the background aerosol, the laser's frequency drift and spectral purity, the depolarization measurement, and the atmospheric temperature. The total systematic error of the backscatter measurement is $4 \%$ to $5 \%$ within the dust layer from the ground up to $4.5 \mathrm{~km}$ ASL and comparable to the statistical error.

In the case of the aerosol extinction coefficient, the systematic error was derived from the error of the AOT measurement by means of differentiation. Figure 10(b) shows the profiles of the relative systematic
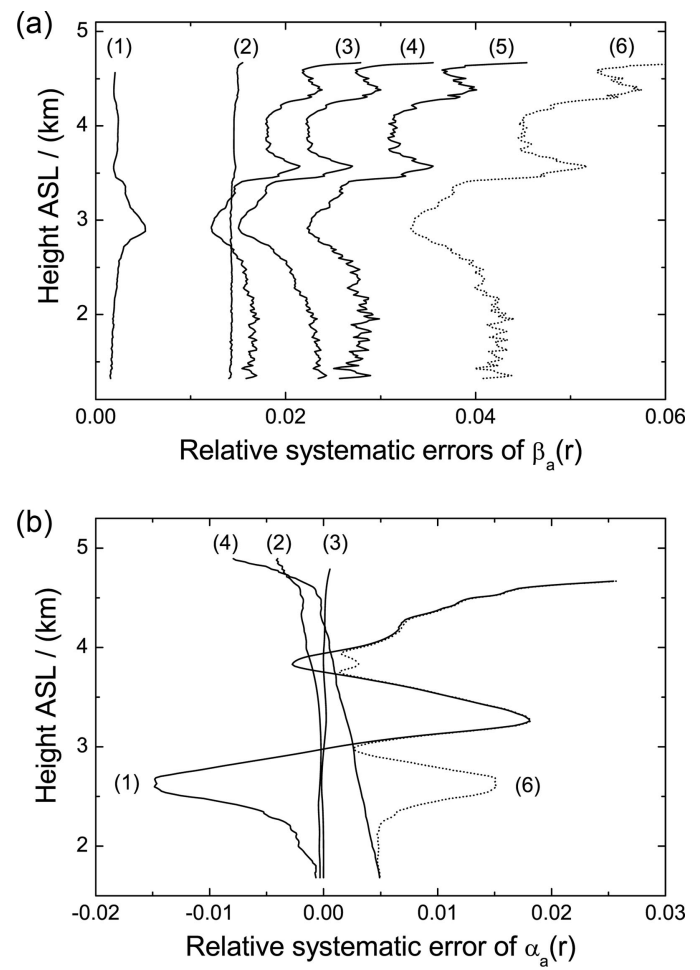

Fig. 10. Relative systematic errors of the (a) aerosol backscatter and (b) extinction measurement arising from the uncertainties in (1) spectral purity, (2) atmospheric temperature, (3) normalization, (4) laser frequency, (5) depolarization ratio, and (6) total error. error of the aerosol extinction coefficient caused by the different error sources. In contrast to the backscatter measurement, spectral impurity caused by multimode laser shots influences the extinction measurement considerably and errors due to normalization, atmospheric temperature variations, and laser frequency fluctuations can be neglected. The magnitude of the error induced by spectral impurity significantly depends on the ratio of $\kappa_{a} / \kappa_{m}(r)$. The small value of $\kappa_{a}$ in our experiments allows for the relative imprecise determination of $\Delta \kappa_{a}$. Again, the individual errors haven been added in quadrature to calculate the total error. The relative systematic error of the extinction coefficient is less than $3 \%$ within the dust layer, so that the statistical deviation with $10 \%-20 \%$ is dominant. However, the statistical error can further be reduced by means of longer averaging times and increasing length of the smoothing window. The error analysis of the AOT measurement using the discussed uncertainties achieves an AOT detection limit of 0.008 .

\section{Comparison with Raman Lidar and Sun Photometer Measurements}

During the SAMUM field campaign both Raman lidar and sunphotometer measurements as well as radio soundings were conducted at the Ouarzazate ground station by IFT. The Raman lidar Backscatter Extinction lidar-Ratio Temperature Humidity Profiling Apparatus (BERTHA) utilizes two frequency

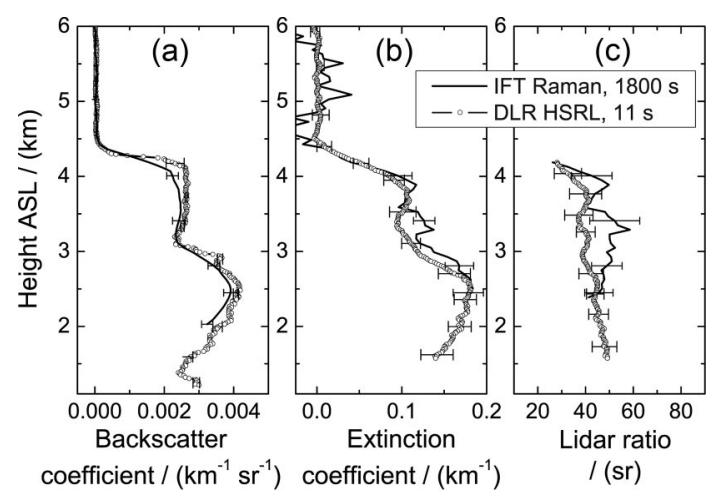

Fig. 11. Comparison of IFT Raman and DLR HSRL (a) backscatter, (b) extinction, and (c) lidar ratio profiles at $532 \mathrm{~nm}$ over Ouarzazate on 3 June 2006 at 04:14 UTC. The vertical resolution is $300 \mathrm{~m}$ for the Raman measurements and the HSRL extinction coefficient and lidar ratio. The vertical resolution is $15 \mathrm{~m}$ for the HSRL backscatter coefficient profile. The averaging time is $11 \mathrm{~s}$ for the HSRL and $1800 \mathrm{~s}$ for the Raman lidar, respectively. The error bars indicate the $3 \sigma$ statistical error. 


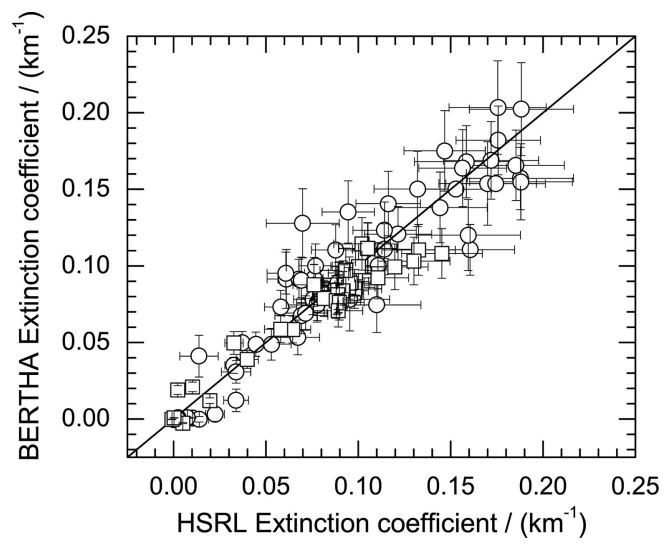

Fig. 12. Correlation of extinction coefficient profiles measured by IFT Raman lidar, BERTHA, and DLR HSRL at six aircraft overpasses during the first SAMUM field phase in May-June 2006. Squares denote the comparison to rotational Raman lidar; circles indicate vibrational Raman measurements. The error bars indicate a relative statistical deviation of $15 \%$.

stabilized Nd:YAG and two Ti:sapphire lasers to generate laser emission at six wavelengths. The receiver provides 14 channels altogether to detect atmospheric backscatter separated in elastic, vibrational, and rotational Raman shifted and depolarized backscatter. A detailed description of the lidar system can be found in [38]. During SAMUM the vibrational (387 and $607 \mathrm{~nm}$ ) and rotational (532 nm) Raman channels were used to directly measure profiles of the aerosol extinction and backscatter coefficients. For intercomparison with the airborne HSRL, the Raman lidar measurements were coordinated with the aircraft overpasses. Because of atmospheric variability, the averaging in time and space was chosen to be as short as possible for both instruments. Figure 11 shows a comparison of airborne HSRL and ground-based Raman lidar measurements taken at night on 3 June 2006. The HSRL profiles were averaged over $11 \mathrm{~s}$ at 04:14 UTC during the direct overpass of the aircraft over the Raman lidar at Ouarzazate. The error bars indicate the $3 \sigma$ statistical error. For intercomparison, the Raman lidar measurements were averaged from 03:56 to 04:26 UTC. The vertical resolution is $300 \mathrm{~m}$ in case of the Raman lidar measurements and the HSRL extinction coefficient and lidar ratio profile. The HSRL backscatter coefficient was measured with $15 \mathrm{~m}$ vertical resolu- tion. As can be seen, the results of HSRL and Raman lidar agree very well within the measurement uncertainty. Because of the different averaging times of both instruments, temporal and spatial variations of the dust layers over Ouarzazate must be taken into account.

To provide a more quantitative comparison of both instruments, Fig. 12 shows a correlation of the extinction coefficient profiles derived from measurements with both instruments for six aircraft overpasses during the SAMUM campaign. Typical averaging times for the HSRL range from 5-10 $\mathrm{s}$ in order to keep spatial atmospheric variations small. The averaging intervals for the Raman lidar were usually 60-120 min depending on the homogeneity of the dust layer. Assuming a typical wind speed of $5 \mathrm{~m} / \mathrm{s}$ within the dust layers the averaging periods correspond to a horizontal range of $1-2 \mathrm{~km}$ in case of the HSRL measurements and of $18-36 \mathrm{~km}$ for the Raman lidar measurements. A linear least-squares fit of the 98 data points leads to a slope value of 0.97 with an error of 0.03 and a $y$-axis intercept of 0.004 indicating an excellent correlation of the data. A linear "robust" fit using a least-absolute deviation method, which can be more applicable in case of outliers and strong scattering of the data, results in a slope value of 0.98 and a $y$-axis intercept of 0.003 .

For validation purposes, the HSRL measurement of the AOT has been compared to sunphotometer measurements conducted by IFT at Ouarzazate throughout the SAMUM field campaign. During one flight mission toward Portugal the HSRL measurement could be compared to an AERONET sunphotometer located at Cabo da Roca $\left(38.5^{\circ} \mathrm{N}, 9.5^{\circ} \mathrm{W}\right)$. In Table 3 the AOT measured by sunphotometers and HSRL are listed. The AOT measured by HSRL was determined from the AOT profile as the mean of the last five range bins above ground. The corresponding error is given by the standard deviation. To minimize the influence of horizontal atmospheric variations, the HSRL averaging times are less than $20 \mathrm{~s}$. The AOT measured by the airborne HSRL at $532 \mathrm{~nm}$ is compared to sunphotometer measurements at 440, 675 , and, if available, $500 \mathrm{~nm}$. Within the limits of uncertainty the AOT measured with both instruments deviate by only 3\% in the worst case. Deviations between these two instruments can arise from several origins. First, the airborne nadir-viewing

Table 3. Comparison of Aerosol Optical Thickness Measured with HSRL and Sunphotometers During the SAMUM Field Campaign in 2006 ${ }^{a}$

\begin{tabular}{|c|c|c|c|c|c|c|c|}
\hline Date & Location & $\begin{array}{l}\text { Time } \\
\text { (UTC) }\end{array}$ & $\begin{array}{c}\mathrm{SP} \\
440 \mathrm{~nm}\end{array}$ & $\begin{array}{c}\mathrm{SP} \\
500 \mathrm{~nm}\end{array}$ & $\begin{array}{c}\mathrm{SP} \\
675 \mathrm{~nm}\end{array}$ & $\begin{array}{c}\text { HSRL } \\
532 \mathrm{~nm}\end{array}$ & $\begin{array}{c}\text { Normalization } \\
\text { Height } \\
\text { (km ASL) }\end{array}$ \\
\hline 19 May & Ouarzazate & 10:55:05 & 0.431 & 0.423 & 0.392 & $0.38 \pm 0.03$ & 8.2 \\
\hline 27 May & Cabo da Roca & $10: 20: 53$ & 0.439 & - & 0.411 & $0.42 \pm 0.03$ & 7.3 \\
\hline 3 June & Ouarzazate & $07: 31: 40$ & 0.435 & 0.431 & 0.413 & $0.40 \pm 0.02$ & 8.5 \\
\hline 4 June & Ouarzazate & 09:56:50 & 0.407 & 0.408 & 0.368 & $0.40 \pm 0.02$ & 8.4 \\
\hline 4 June & Ouarzazate & $10: 41: 51$ & 0.447 & 0.450 & 0.429 & $0.44 \pm 0.02$ & 8.4 \\
\hline
\end{tabular}

${ }^{a}$ SP: aerosol optical thickness measured by sunphotometry at the respective wavelength; normalization height: height ASL chosen for normalization. 
HSRL determines the AOT between the normalization height, which is close to the flight level, and the ground. In contrast, a sunphotometer measures the AOT of the entire atmospheric column. Thus, compared to sunphotometry, the HSRL values of the AOT are systematically reduced by the amount of AOT above flight level. However, this residual amount is usually very small compared to the AOT of the lower atmospheric column and can be neglected in case of high flight altitudes. Second, deviations of the results of both instruments can be attributed to the measurement geometry. The airborne HSRL strictly measures in nadir configuration, whereas a Sun tracking photometer has arbitrary hemispherical viewing angles. Thus, horizontal variations in the dust stratification and composition can lead to deviations of the measured AOT, especially in the early morning or late evening.

\section{Conclusions}

We have developed an airborne high spectral resolution lidar based on an iodine vapor absorption filter and a high-power, frequency-doubled Nd:YAG laser. The HSRL separates the aerosol contribution from the atmospheric backscatter and thereby measures aerosol backscatter and extinction coefficients directly. With the use of a dual-pass optical configuration, strong suppression of aerosol backscatter associated with a high degree of transmission of molecular backscatter and compact mechanical dimensions is achieved. Due to the system's favorable transmitter and receiver properties, atmospheric cross sections of aerosol extinction, optical thickness, and lidar ratio can be measured with high vertical and horizontal resolution. In contrast to Raman lidars, the averaging times of the HSRL can be as short as a few seconds. Thus, the HSRL can be used advantageously for airborne operation. Its performance aboard the DLR Falcon research aircraft during the first SAMUM field phase proved to be stable and reliable. With this instrument optical properties of pure Saharan dust were measured close to its source regions for the first time, to the best of our knowledge. The relative systematic error of the backscatter coefficient has been evaluated to be less than $5 \%$ for backscatter coefficients higher than $7.2 \times 10^{-4}$ $\mathrm{sr}^{-1} \mathrm{~km}^{-1}$. For the extinction measurement, the relative systematic error is less than $3 \%$ within the dust layer. The HSRL results were compared to Raman lidar measurements as well as sunphotometry. In the case of Raman lidar measurements the comparison of extinction and backscatter profiles has shown agreement of both instruments within their combined limits of uncertainty. In the case of sunphotometers, the agreement of the measured AOT is excellent considering the different measurement ranges and geometries of both techniques. The airborne HSRL is a valuable instrument to study the optical properties of various aerosol types and their transportation and mixing processes.
This work was supported by the German Research Foundation (DFG) under grant FOR 539-PE 632/2, the European Space Agency (ESA) under contract 19429/06/NL/AR, and the European Fleet for Airborne Research (EUFAR) as part of the Desert Dust and Biomass Burning Aerosols over Portugal (DARPO) project. We thank Albert Ansmann (IFT) and Frank Wagner of the Centro de Geofisica, Universidade de Evora, Portugal, for providing the sunphotometer data and Bernadett Weinzierl (DLR) for the analyses of the aerosol in situ measurements. Two anonymous reviewers provided helpful suggestions and comments. We greatly appreciate the scientific coordination of the Falcon flight missions by Andreas Petzold (DLR) during the SAMUM field campaign in Morocco.

\section{References}

1. J. A. Coakley, R. D. Cess, and F. B. Yurevich, "The effect of troposheric aerosols on the earth's radiation budget: a parameterization for climate models," J. Atmos. Sci. 40, 116-138 (1983).

2. J. D. Klett, "Stable analytical inversion solution for processing lidar returns," Appl. Opt. 20, 211-220 (1981).

3. A. Ansmann and D. Müller, "Lidar and atmospheric aerosol particles," in Lidar: range-resolved optical remote sensing of the atmosphere, C. Weitkamp, ed. (Springer, 2005), pp. 105-142.

4. D. N. Whiteman, I. Veselovskii, M. Cadirola, K. Rush, J. Comer, J. R. Potter, and R. Tola, "Demonstration measurements of water vapor, cirrus clouds, and carbon dioxide using a high-performance Raman lidar," J. Atmos. Ocean. Technol. 24, 1377-1388 (2007).

5. S. T. Shipley, D. H. Tracy, E. W. Eloranta, J. T. Trauger, J. T. Sroga, F. L. Roesler, and J. A. Weinman, "High spectral resolution lidar to measure optical scattering properties of atmospheric aerosols. 1: Theory and instrumentation," Appl. Opt. 22, 3716-3724 (1983).

6. H. Shimizu, S. A. Lee, and C. Y. She, "High spectral resolution lidar system with atomic blocking filters for measuring atmospheric parameters," Appl. Opt. 22, 1373-1381 (1983).

7. R. J. Alvarez, L. M. Caldwell, Y. H. Li, D. A. Krueger, and C. Y. She, "High-spectral-resolution lidar measurement of troposheric backscatter-ratio with barium atomic blocking filters," J. Atmos. Ocean. Technol. 7, 876-881 (1990).

8. J. W. Hair, L. M. Caldwell, D. A. Krueger, and C. Y. She, "High-spectral-resolution lidar with iodine-vapor filters: measurement of atmospheric-state and aerosol profiles," Appl. Opt. 40, 5280-5294 (2001).

9. P. Piironen and E. W. Eloranta, "Demonstration of a highspectral-resolution lidar based on an iodine absorption filter," Opt. Lett. 19, 234-236 (1994).

10. Z. Liu, I. Matsui, and N. Sugimoto, "High-spectral-resolution lidar using an iodine absorption filter for atmospheric measurements," Opt. Eng. 38, 1661-1670 (1999).

11. U. Wandinger, D. Müller, C. Böckmann, D. Althausen, V. Matthias, J. Bösenberg, V. Weiss, M. Fiebig, M. Wendisch, A. Stohl, and A. Ansmann, "Optical and microphysical characterization of biomass-burning and industrial-pollution aerosols from multiwavelength lidar and aircraft measurements," J. Geophys. Res. 107(D21), 8125, doi:10.1029/2000JD000202 (2002).

12. R. Ferrare, C. Hostetler, J. Hair, A. Cook, D. Harper, S. Burton, M. Clayton, A. Clarke, P. Russell, and J. Redemann, "Airborne high spectral resolution lidar aerosol measurements during MILAGRO and TEXAQS/GOMACCS," presented at 
the 87th Annual Meeting of the American Meteorological Society, San Antonio, Texas, 14-18 January 2007.

13. A. Stoffelen, J. Pailleux, E. Källn, J. M. Vaughan, L. Isaksen, P. Flamant, W. Wergen, E. Andersson, H. Schyberg, A. Culoma, R. Meynart, M. Endemann, and P. Ingmann, "The Atmospheric Dynamics Mission for global wind field measurement," Bull. Am. Meteorol. Soc. 86, 73-87 (2005).

14. A. Ansmann, U. Wandinger, O. Le Rille, D. Lajas, and A. G. Straume, "Particle backscatter and extinction profiling with the spaceborne high-spectral-resolution Doppler lidar ALADIN: methodology and simulations," Appl. Opt. 46, 6606-6622 (2007).

15. A. Petzold, B. Weinzierl, M. Esselborn, G. Ehret, M. Fiebig, A. Fix, C. Kiemle, K. Rasp, and M. Wirth, "Technical support of the EarthCARE Mission for the validation of spaceborne aerosol products during the Saharan Mineral Dust Experiment," European Space Research and Technology Centre (ESTEC) contract 19429/06/NL/AR (2007).

16. H. C. van de Hulst, Light Scattering by Small Particles (Wiley, 1975).

17. R. Miles, W. Lempert, and J. Forkey, "Laser Rayleigh scattering," Meas. Sci. Technol. 12, 33-51 (2001).

18. A. Young, "Rayleigh scattering," Appl. Opt. 20, 533-535 (1981).

19. C. Y. She, "Spectral structure of laser light scattering revisited: bandwidths of nonresonant scattering lidars," Appl. Opt. 40, 4875-4884 (2001).

20. S. Gerstenkorn and P. Luc, Atlas du Spectre D'Absorption de la Molecule D'Iode. Atlas III (Edition du CNRS, 1978).

21. G. Tenti, C. D. Boley, and R. C. Desai, "On the kinetic model description of Rayleigh-Brillouin scattering from molecular gases," Can. J. Phys. 52, 285-290 (1974).

22. A. T. Young and G. W. Kattawar, "Rayleigh-scattering line profiles," Appl. Opt. 22, 3668-3670 (1983).

23. J. N. Forkey, Precision Optics Corporation, 22 East Broadway, Gardner, Massachusetts 01440 (personal communication, 2005).

24. J. N. Forkey, W. R. Lempert, and R. B. Miles, "Corrected and calibrated $I_{2}$ absorption model at frequency-doubled Nd:YAG wavelengths," Appl. Opt. 36, 6729-6738 (1997).

25. G. W. Kattawar, A. T. Young, and T. J. Humphreys, "Inelastic scattering in planetary atmospheres. 1 . The Ring effect, without aerosols," Astrophys. J. 243, 1049-1057 (1981).

26. R. M. Measures, Laser Remote Sensing: Fundamentals and Applications (Wiley, 1984).
27. B. A. Bodhaine, N. B. Wood, E. G. Dutton, and J. R. Slusser, "On Rayleigh optical depth calculations," J. Atmos. Ocean. Technol. 16, 1854-1861 (1999).

28. A. Savitzky and M. J. E. Golay, "Smoothing and differentiation of data by simplified least square procedures," Anal. Chem. 36, 1627-1639 (1964).

29. J. Biele, G. Beyerle, and G. Baumgarten, "Polarization lidar: corrections of instrumental effects," Opt. Express 7, 427-435 (2000).

30. A. Behrendt and T. Nakamura, "Calculation of the calibration constant of polarization lidar and its dependency on atmospheric temperature," Opt. Express 10, 805-817 (2002).

31. R. A. Ferrare, D. D. Turner, L. H. Brasseur, W. F. Feltz, O. Dubovik, and T. P. Tooman, "Raman lidar measurements of the aerosol extinction-to-backscatter ratio over the Southern Great Plains," J. Geophys. Res. 106, 20333-20348 (2001).

32. M. Tesche, A. Ansmann, D. Müller, D. Althausen, R. Engelmann, M. Hu, and Y. Zhang, "Particle backscatter, extinction, and lidar ratio profiling with Raman lidar in south and north China," Appl. Opt. 46, 6302-6308 (2007).

33. G. Poberaj, A. Fix, A. Assion, M. Wirth, C. Kiemle, and G. Ehret, "Airborne all-solid-state DIAL for water vapour measurements in the tropopause region: system description and assessment of accuracy," Appl. Phys. B 75, 165-172 (2002).

34. G. Ehret, H. H. Klingenberg, U. Hefter, A. Assion, A. Fix, G. Poberaj, S. Berger, S. Geiger, and Q. Lü, "High peak and average power all-solid-state laser systems for airborne lidar applications," LaserOpto 32, 29-37 (2000).

35. R. L. Schmitt and L. A. Rahn, "Diode-laser-pumped Nd:YAG laser injection seeding system," Appl. Opt. 25, 629-633 (1986).

36. M. Fiebig, C. Stein, F. Schröder, P. Feldpausch, and A. Petzold, "Inversion of data containing information on the aerosol particle size distribution using multiple instruments," J. Aerosol Sci. 36, 1353-1372 (2005).

37. A. Petzold, M. Fiebig, H. Flentje, A. Keil, U. Leiterer, F. Schröder, A. Stifter, M. Wendisch, and P. Wendling, "Vertical variability of aerosol properties observed at a continental site during the Lindenberg Aerosol Characterization Experiment (LACE 98)," J. Geophys. Res. 107(D21), 8125, doi:10.1029/ 2001JD001043 (2002).

38. D. Althausen, D. Müller, A. Ansmann, U. Wandinger, H. Hube, E. Clauder, and S. Zörner, "Scanning 6-wavelength 11-channel aerosol lidar," J. Atmos. Ocean. Technol. 17, 1469-1482 (2000). 